\title{
Effects of Eccentric Exercise on Cycling Efficiency
}

\author{
Joaquin Sanchis Moysi ${ }^{1}$, Jerónimo Carmelo Garcia-Romero², \\ José Ramón Alvero-Cruz ${ }^{2}$, Germán Vicente-Rodriguez ${ }^{1}$, Ignacio Ara ${ }^{1}$, \\ Cecilia Dorado ${ }^{1}$, and José A.L. Calbet ${ }^{1}$
}

\begin{abstract}
Catalogue Data
Sanchis Moysi, J.; Garcia-Romero, J.C.; Alvero-Cruz, J.R.; Vicente-Rodriguez, G.; Ara, I.; Dorado, C.; and Calbet, J.A.L. (2005). Effects of eccentric exercise on cycling efficiency. Can. J. Appl. Physiol. 30(3): 259-275. (C) 2005 Canadian Society for Exercise Physiology.
\end{abstract}

Key words: performance, fatigue, muscle soreness, lactate, triathlon

Mots-clés: performance, fatigue, douleur musculaire, lactate, triathlon

\begin{abstract}
Résumé
The aim of this study was to find out whether the efficiency of concentric muscle contraction is impaired by eccentric squatting exercise. The study involved 25 male physical education students in two experiments. In the first experiment 14 subjects undertook cycling exercise at $65 \% \dot{\mathrm{V}} \mathrm{O}_{2}$ max until exhaustion on two occasions. During the experimental condition their cycling was interrupted every $10 \mathrm{~min}$ so they could perform eccentric squatting exercise, whereas in the control condition they rested seated on the bike during the interruptions. Eccentric squatting consisted of 10 series of 25 reps with a load equivalent to $150 \%$ of the subject's body mass on the shoulders. During the first experiment gross efficiency decreased (mean $\pm S E$ ) from $17.1 \pm 0.3$ to $16.0 \pm 0.4 \%$, and from $17.2 \pm 0.3$ to $16.5 \pm 0.4 \%$, between the 2 nd and 9 th cycling bouts of the experimental and control conditions, respectively (both $p<0.05)$. The reduction in cycling efficiency was similar in both conditions $(p=0.10)$. Blood lactate concentration [La] was higher during the experimental than in the control condition ( $p<0.05)$, but substrate oxidation was similar. MVC was decreased similarly (25-28\%) in both conditions. The 11 subjects participating in the second experiment undertook 25 reps of eccentric squatting exercise only, each with a load equivalent to $95 \%$ of his maximal voluntary contraction $(M V C)$, repeated every 3 min until exhaustion. One hour
\end{abstract}

${ }^{1}$ Departamento de Educación Física, Campus Universitario de Tafira, 35017 Las Palmas de Gran Canaria, Canary Islands, Spain; ${ }^{2}$ School of Sports Medicine, Dept. of Human Physiology and Physical Education, University of Málaga, Avda. Cervantes 2, 29071 Málaga, Spain. 
after the end of the eccentric squatting exercise series cycling, $\dot{V} \mathrm{O}_{2}$ and gross cycling efficiency were comparable to the values observed before the eccentric exercise. Both experimental protocols with eccentric exercise elicited similar muscle soreness 2 days later; however, at this time cycling efficiency was similar to that observed prior to eccentric exercise. The interposition of cycling exercise between the eccentric exercise bouts accelerated the recovery of MVC. We conclude that eccentric exercise does not alter or has only a marginal effect on gross cycling efficiency even in presence of marked muscle soreness.

Le but de cette étude est de vérifier si l'efficacité d'une action musculaire miométrique est réduite par un exercice pliométrique de flexion accroupie des jambes. Les sujets sont 25 étudiants en éducation physique participent à deux séances d'expérimentation. Durant la première séance, 14 sujets accomplissent jusqu'à épuisement et en deux occasions, un exercice de pédalage à une intensité correspondant à $65 \%$ du $\dot{V O}_{2}$ max. Au cours de cette condition expérimentale, l'exercice de pédalage est interrompu toutes les 10 min pour permettre la réalisation des flexions accroupies; pendant cette période d'interruption, en la condition de contrôle les sujets restent assis sur la bicyclette. Les exercices de flexion accroupie consistent en 10 séries de 25 répétitions avec une charge portée sur les épaules et équivalente à $150 \%$ de la masse corporelle. Durant la première séance d'expérimentation, l'efficacité brute passe de 17,1 $\pm 0,3$ à 16,0 $\pm 0,4 \%$, et de $17,2 \pm 0,3$ à 16,5 $\pm 0,4 \%$ entre la $2^{e}$ et la $9^{e}$ série d'exercices de pédalage en condition expérimentale et en condition de contrôle, respectivement ( $p<0,05$ dans les deux cas). La baisse d'efficacité est similaire dans les deux conditions $(p=0,10)$. La concentration sanguine de lactate est plus forte dans la condition expérimentale que dans la condition de contrôle ( $p<0,05)$, mais l'oxydation des substrats est du même ordre. Les 11 sujets participant à la deuxième séance d'expérimentation n'ont fait, par intervalle de 3 min jusqu'à épuisement, que des séries de 25 répétitions d'exercices de flexion accroupie, chaque série étant accomplie avec une charge équivalente à $95 \%$ de leur force maximale volontaire (MVC). Une heure après les séries d'exercices pliométriques, le $\dot{V}_{2}$ sur bicyclette et l'efficacité mécanique brute ont des valeurs comparables aux valeurs mesurées avant les exercices pliométriques. Les deux protocoles expérimentaux incluant des exercices pliométriques ont causé des douleurs musculaires 2 jours plus tard; à ce moment, l'efficacité mécanique était semblable à l'efficacité mesurée avant les exercices pliométriques. L'ajout d'un exercice de pédalage entre les séries d'exercices pliométriques a accéléré le retour à la normale de MVC. En conclusion, les exercices pliométriques ont peu ou pas d'effet sur l'efficacité mécanique brute même en présence de douleur musculaire importante.

\section{Introduction}

Eccentric exercise induces delayed-onset muscle soreness, muscle fibre disruption, and functional impairment, as shown by the concomitant decrease in maximal voluntary contraction (MVC) and maximal power output (Appell et al., 1992; Cheung et al., 2003; Lieber et al., 1996; Rodenburg et al., 1993; Yu et al., 2003). Whether these architectural and functional changes could also decrease the efficiency of muscle contraction remains unknown. It has also been shown that the energy cost of running increases with the distance covered during a marathon (Brueckner et al., 1991) and at the end of the marathon (Kyrolainen et al., 2000). With time, the increase in the $\mathrm{O}_{2}$ cost of running is even more accentuated during downhill running (Dick and Cavanagh, 1987) than during running on level ground, 
i.e., during a mode of exercise characterised by a significant component of eccentric muscle actions.

It is likely that eccentric exercise causes muscle damage by a progressive mechanical disruption, the magnitude of which depends on the intensity, velocity, amplitude, duration of eccentric contractions, and previous experience with this type of muscle contraction (Cheung et al., 2003; Nosaka et al., 2002). After the initial mechanical disruption during the hours that follow, histological changes take place which are compatible with a local inflammatory reaction that causes secondary damage and the characteristic muscle pain (Lieber and Friden, 1999; Peterson et al., 2003; Tidball, 2002; Warren et al., 1999). It has also been reported that muscle soreness is associated with decreased running economy in trained subjects (Braun and Dutto, 2003; Calbet et al., 2001). Warren et al. (1996) have shown that eccentric exercise reduces concentric contraction economy in the muscle of the mouse. Human experiments also suggest that concentric muscle contractions are likewise impaired following exhaustive eccentric exercise, but to a lesser extent than eccentric contractions (Horita et al., 2003). No attempt has been made until now, however, to verify whether muscle efficiency during concentric contractions is progressively altered by the accumulated effect of repetitive eccentric muscle actions until exhaustion.

It seems there is less muscle damage when a bout of concentric exercise (Nosaka and Clarkson, 1997) or a warm-up is performed before eccentric exercise (Evans et al., 2002). But it is still not known whether prolonged concentric exercise may actually have a protective effect in attenuating the muscle damage and functional impairment caused by repeated bouts of eccentric exercise. Thus, we hypothesise that cycling efficiency will be impaired by eccentric exercise and that this effect will increase as a function of the number of prior eccentric contractions.

Therefore, the aim of this study was to find out whether the efficiency of concentric muscle contraction is impaired by eccentric exercise, and to describe the time course of this impairment. Additionally we aimed to determine how much time is required to recover the normal values of muscle efficiency if affected by eccentric exercise. To achieve these objectives, we measured cycling efficiency during cycling at $65 \%$ of $\dot{\mathrm{VO}}_{2}$ max until exhaustion. In one group of subjects, eccentric exercise bouts were interposed every $10 \mathrm{~min}$ of the cycling exercise (Experiment 1). The recovery process was monitored by determining cycling efficiency $24 \mathrm{hrs}, 48 \mathrm{hrs}$, and 4 days after the prolonged exhaustive exercise. In separate experiments designed to further clarify whether concentric exercise has a protective effect on functional alterations induced by eccentric exercise, cycling efficiency, muscular strength, and the cardiorespiratory response to exercise were assessed before, then 1 hour, 2 days, and 7 days after repeated eccentric squatting exercise to exhaustion (Experiment 2). During the latter experiments no concentric exercise was performed between the bouts of eccentric exercise.

\section{Methods}

\section{SUBJECTS}

Twenty-five male physical education students volunteered to participate in this study after providing written informed consent. They were split into two groups, 
Table 1 Physical Characteristics

\begin{tabular}{|c|c|c|c|c|}
\hline & \multicolumn{2}{|c|}{ Concentric-eccentric $(n=14)$} & \multicolumn{2}{|c|}{ Pure eccentric $(n=11)$} \\
\hline & Mean & $S E$ & Mean & $S E$ \\
\hline Age (years) & 22.7 & 1.0 & 24.9 & 1.1 \\
\hline Height $(\mathrm{cm})$ & 177 & 1 & 177 & 2 \\
\hline Body mass (kg) & 72.1 & 1.6 & 76.5 & 2.8 \\
\hline Percentage body fat & 13.7 & 0.7 & 14.4 & 1.5 \\
\hline$\dot{\mathrm{V}} \mathrm{O}_{2} \max \left(\mathrm{ml} \cdot \mathrm{kg}^{-1} \cdot \mathrm{min}^{-1}\right)$ & 56.1 & 1.2 & 48.8 & 1.9 \\
\hline
\end{tabular}

one group per experiment: concentric-eccentric (Experiment 1) and eccentric (Experiment 2). Their physical characteristics are reported in Table 1. Fourteen subjects agreed to participate in the concentric-eccentric experiments and 11 took part in the eccentric experiments. All were healthy physically active young men who exercised regularly 2 to 4 times a week. They were asked to follow similar diets and to avoid strenuous physical activities during the 48 hours prior to the experiments. The studies reported here were approved by the local ethics committee.

\section{EXPERIMENT 1: CONCENTRIC-ECCENTRIC EXERCISE}

Subjects reported to the laboratory on 6 occasions. During the first two visits they were familiarised with the experimental protocol. The third session was used to measure their $\dot{\mathrm{VO}}_{2} \max (\mathrm{CPX}$, Medical Graphics, St. Paul, MN) during an incremental exercise $\left(25 \mathrm{~W} \cdot \mathrm{min}^{-1}\right.$, at $\left.70 \mathrm{rev} \cdot \mathrm{min}^{-1}\right)$ to exhaustion on the cycle ergometer (Ergo-metrics 900, Ergo-line, Bitz, Germany) (Dorado et al., 2004). Thereafter, the load eliciting a $\dot{\mathrm{VO}}_{2}$ corresponding to $65 \%$ of $\dot{\mathrm{VO}}_{2}$ max was determined and verified. Subsequently, subjects reported two more times to the laboratory and were randomly assigned to a control $(\mathrm{CON})$ or to an eccentric exercise trial (ECC) which were conducted 3 weeks apart. Trials consisted of 10 bouts of cycling exercise at $65 \%$ of $\dot{\mathrm{VO}}_{2} \max$, each lasting for $10 \mathrm{~min}$, except the first bout which was extended to $20 \mathrm{~min}$. During the CON trial, rest periods of 3 min were intercalated between cycling bouts, while during the ECC trial this time was used to perform 25 reps of "eccentric squatting exercise" (Carreño et al., 2001) between cycling bouts (Figure 1).

Eccentric exercise was performed by lowering a weightlifting barbell with a load equivalent to $150 \%$ body mass, which was placed on the shoulders. Each repetition started from the upright position. Subjects then had to bend their knees until reaching the final position, which was defined by achievement of a $90 \mathrm{E}$ knee angle. Once the final position was reached, two assistants at each side raised the load to the upright position. Just before each experiment, the maximal isometric leg extension force was measured while subjects stood on a force plate (Kistler, Winterthur, Switzerland) with the knees bent at a $90^{\circ}$ angle. The force developed 


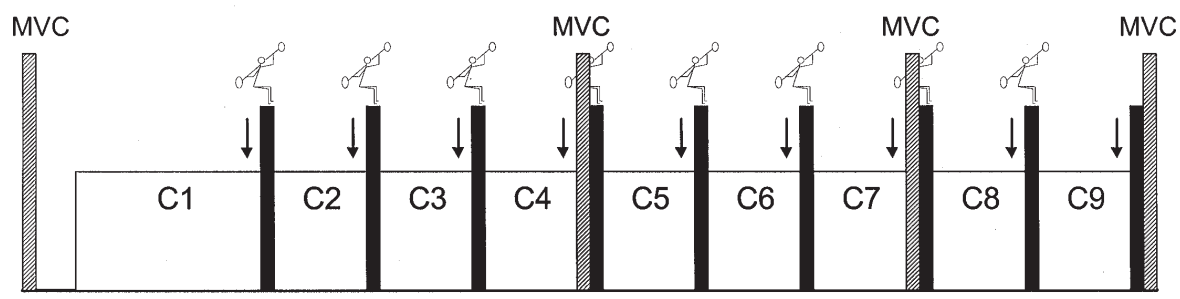

Figure 1. Experimental protocol. Vertical arrows represent blood sample points. MVC: assessment of maximal voluntary contraction in squatting position (knees bent at $90^{\circ}$ ). The picture represents the scheme followed during the concentric-eccentric condition, while during the control condition the phases of eccentric exercise were replaced by 3 min of rest. C1....C9 represent the bouts of bicycling exercise. Vertical arrows signal blood sampling points.

was transmitted to the force plate when the subjects pushed maximally against a weightlifting bar placed on the shoulders and attached to the floor with two steel chains, one at each side of the force plate.

Force measurements were repeated after the 4th and 8th cycling bouts, as well as at the end of the test. During the last 4 minutes of each bout, $\dot{\mathrm{VO}}{ }_{2}, \dot{\mathrm{VCO}}{ }_{2}$, minute ventilation $\left(\mathrm{V}_{\mathrm{E}}\right)$, respiratory rate $(\mathrm{RR})$, tidal volume $\left(\mathrm{V}_{\mathrm{t}}\right)$, end-tidal $\mathrm{O}_{2}$ pressure $\left(\mathrm{P}_{\mathrm{ET}} \mathrm{O}_{2}\right)$, and end-tidal $\mathrm{CO}_{2}$ pressure $\left(\mathrm{P}_{\mathrm{ET}} \mathrm{CO}_{2}\right)$ were measured with a metabolic chart (CPX, Medical Graphics) and averaged. Heart rate was recorded with a Polar Avantage XL heart rate monitor (Sport Tester 4000, Polar, Kempele, Finland). In addition, whole blood lactate concentration ([La]) was assessed in capillary blood obtained from the ear lobe during the last minute of each cycling bout (YSI 1500 Sport, Yellow Springs, OH). Prior to exercise the ear lobe was hyperemized with Finalgon ${ }^{\circledR}$. To reduce thermal stress and minimise water losses due to sweating, subjects were fan cooled and drank approximately $100 \mathrm{ml}$ of water during the rest periods. Tests were performed at $20-24{ }^{\circ} \mathrm{C},-70 \%$ relative humidity, and 740-750 $\mathrm{mmHg}$ atmospheric pressure.

One, 2, and 4 days later the subjects again reported to the laboratory for measurement of MVC, cycling efficiency, [La], and cardiorespiratory response to 20 min of cycling exercise at $65 \%$ of $\dot{\mathrm{VO}}_{2} \mathrm{max}$, as performed during the first bout of cycling exercise during the $\mathrm{CON}$ and ECC conditions. The $\dot{\mathrm{VO}}_{2}, \dot{\mathrm{VCO}_{2}}, \mathrm{~V}_{\mathrm{E}}$, and heart rate (HR) recorded during the last 4 min of exercise were averaged and taken as representative of this exercise intensity. Blood samples for [La] assessment were obtained at approximately the 20th minute of exercise.

\section{EXPERIMENT 2: ECCENTRIC EXERCISE}

Following two familiarisation sessions with the experimental protocol, $\dot{\mathrm{VO}}_{2} \mathrm{max}$ was determined (Table 1). The subjects reported to the laboratory three more times. Each session began with a standardised warm-up followed by the measurement of MVC. The subjects then exercised on the cycle ergometer for $6 \mathrm{~min}$ at $151 \pm 4 \mathrm{~W}$ ( $62 \%$ of their $\dot{\mathrm{VO}}_{2} \mathrm{max}$ ), and the $\dot{\mathrm{VO}_{2}}, \dot{\mathrm{V}} \mathrm{VO}_{2}, \mathrm{~V}_{\mathrm{E}}$, and $\mathrm{HR}$ were determined during 
the last 2 min and averaged. At the 5th minute of exercise a blood sample was obtained for [La] assessment. The next day the subjects undertook a series of 25 reps of eccentric squatting exercise, each with a load equivalent to $95 \%$ of his MVC ( $160 \%$ of body mass). Eccentric exercise series were repeated every 3 min until the subjects could not perform more than 10 reps, or until they could no longer control the movement and/or the technical execution deteriorated. At the end of the eccentric exercise they had an hour to recover. They then repeated the cycling exercise bout at the same intensity as before the eccentric exercise. On Days 2 and 7 following the eccentric exercise, the MVC, cycling efficiency, capillary blood lactate concentration, and cardiorespiratory response to exercise were evaluated again. Although not measured in the current study, the eccentric squatting exercise protocol applied here elicited a four- to fivefold elevation in plasma CK concentration in this population of subjects (Carreño et al., 2001).

\section{GROSS EFFICIENCY AND ASSESSMENT OF MUSCLE SORENESS}

Gross cycling efficiency was calculated from $\dot{\mathrm{VO}}_{2}$ and RER values, using the energy equivalent of $\mathrm{O}_{2}$ corresponding to each RER value (Peronnet and Massicotte, 1991).

To assess muscle pain, we asked the subjects to rate their muscle soreness by assigning a value on a visual scale ranging from 0 to 10 points, where 0 represented no muscle soreness and 10 points represented the highest level of postexercise muscle soreness they ever experienced.

\section{STATISTICAL ANALYSIS}

The influence of eccentric exercise and time on cycling efficiency during prolonged exercise (Experiment 1) was determined by a two-way repeated measures analysis of variance with eccentric exercise (two levels) and time (9 levels, starting with the 2 nd and ending with the 10th bout) as within-subjects factors. We used a similar approach to study the recovery process after Experiment 2, i.e., ANOVA was performed with recovery time (four levels) as a within-subjects factor. In the case of a significant $F$-value, to locate the temporal point at which there was a significant difference between conditions in Experiment 1, we conducted post hoc pairwise comparisons using a paired Student $t$-test corrected with the Bonferroni procedure. When ANOVA was significant in Experiment 2, we conducted pairwise comparisons (control vs. the different time points assessed: $1 \mathrm{hr}, 2$ days, and 7 days following eccentric exercise) using the paired Student $t$-test without corrections for multiple comparisons, to reduce the likelihood of a type II error (Perneger, 1998). We applied the unpaired Student $t$-test to see if there was a significant difference in force impairment and recovery between Experiments 1 and 2. To test whether a variable increased or decreased linearly with time during Experiment 1 , we applied a linear regression analysis. In some instances we report the partial eta-squared value as a measure of the size effect, as well as the power of the particular test. The eta-squared statistic describes the proportion of total variability attributable to a factor. The significance level was set at $p<0.05$. Data are reported as the mean and standard error $(S E)$. 

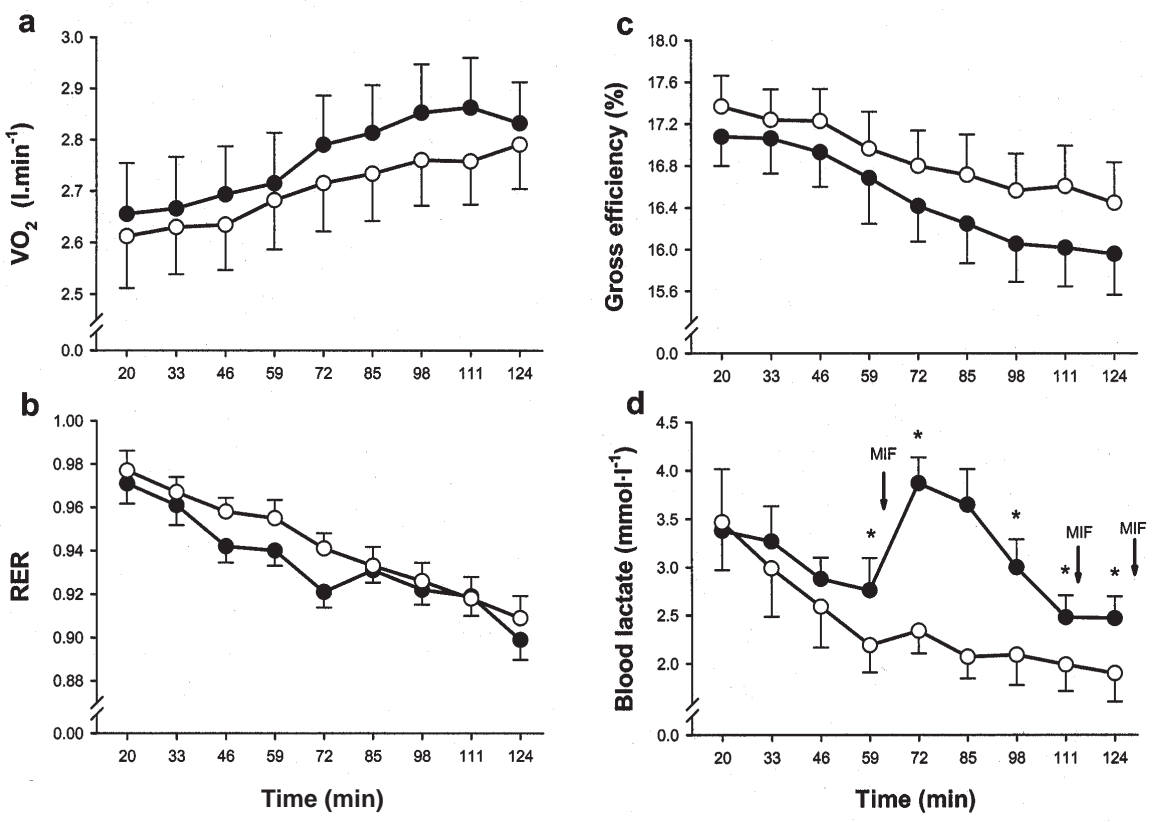

Figure 2. Oxygen uptake, respiratory exchange ratio (RER), gross cycling efficiency, and capillary blood lactate response to prolonged intermittent cycling exercise at $65 \%$ $\dot{\mathrm{V}} \mathrm{O}_{2} \max$. White circles represent the condition without eccentric exercise; black circles represent the condition in which subjects performed 25 reps of eccentric squatting exercise with a load equivalent to $150 \%$ of body mass after each bout of cycling exercise. MVC: measurement of maximal voluntary contraction. ${ }^{*} p<0.05$ when comparing both conditions.

\section{Results}

\section{EXPERIMENT 1}

Despite the fact that the subjects displaced 23,227 $\pm 1,196 \mathrm{~kg}$ (total mass lifted during the experiment) during the exercise protocol with eccentric exercise, $\mathrm{V}_{2}$ was similar in the CON and ECC trials $(p=0.11$; size effect $=0.2$; power $=0.4)$ (Figure 2a). However, in both conditions $\mathrm{VO}_{2}$ increased linearly with time ( $p<$ 0.05 ; size effect $=0.9$; power $=0.9$ ). Between the 2 nd and 9th cycling bouts the mean $\mathrm{VO}_{2}$ was increased by 6.1 and $6.3 \%$, i.e., from $2.63 \pm 0.09$ to $2.79 \pm 0.09$, and from $2.67 \pm 0.10$ to $2.83 \pm 0.08 \mathrm{~L} \cdot \mathrm{min}^{-1}$, in the CON and ECC trials, respectively $(p<0.001)$. In both trials the RER drifted to a lower value with time (from $0.97 \pm$ 0.01 to $0.91 \pm 0.01$, and from $0.96 \pm 0.01$ to $0.90 \pm 0.01$, in the CON and ECC trials, respectively, both $p<0.05$; size effect $=0.8$; power $=1.0$ ), implying an increased contribution of fat oxidation to overall energy yield (Figure $2 b$ ). The increase of fat oxidation accounted for nearly $60 \%$ of the $\mathrm{VO}_{2}$ drift observed between the 2 nd and the last cycling bout.

Gross efficiency was similar in the CON and ECC trials ( $p=0.11$; size effect $=0.2$; power $=0.4)($ Figure $2 \mathrm{c})$. It decreased between the 2 nd and 9th cycling 


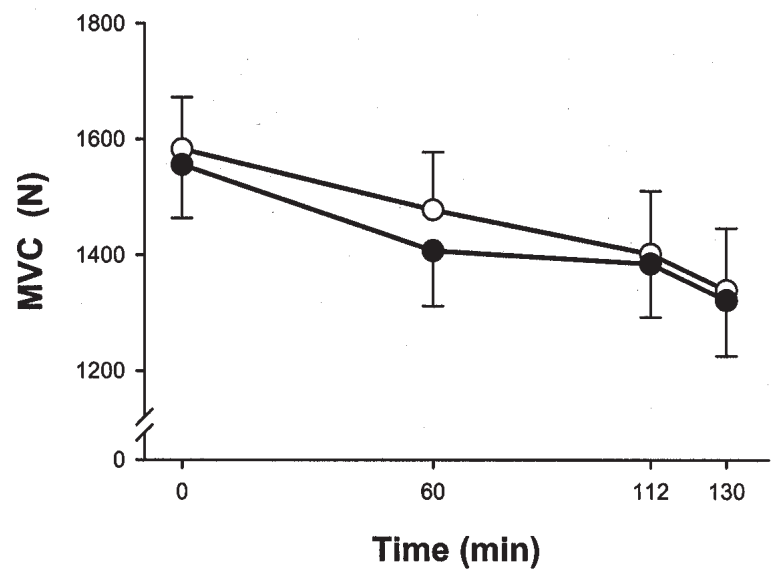

Figure 3. Maximal voluntary contraction (MVC) during prolonged intermittent cycling exercise at $65 \% \dot{\mathrm{VO}}_{2}$ max. White circles represent the condition without eccentric exercise; black circles represent the condition in which subjects performed 25 reps of eccentric squatting exercise with a load equivalent to $150 \%$ of body mass after each bout of cycling exercise. In both conditions force declined significantly with time.

bouts, from $17.2 \pm 0.3$ to $16.5 \pm 0.4 \%$, and from $17.1 \pm 0.3$ to $16.0 \pm 0.4 \%$, in the CON and ECC trials, respectively (both $p<0.05$; size effect $=0.9$; power $=0.9$ ). The reduction in cycling efficiency over time tended to be more accentuated during ECC $(6.0 \%)$ than during CON (4.6\%), as shown by the interaction in the ANOVA analysis $(p=0.10$; size effect $=0.3$; power $=0.1)$ (Figure $2 c)$. Between the 2 nd and 9th cycling bouts, capillary blood lactate concentration also decreased with time in both conditions, from $3.3 \pm 0.4$ to $2.5 \pm 0.3 \mathrm{mmol} \cdot \mathrm{L}^{-1}$, and from $3.0 \pm 0.5$ to 1.9 $\pm 0.3 \mathrm{mmol} \cdot \mathrm{L}^{-1}$ (both $p<0.001$; size effect $=0.2$; power $=1.0$ ), in the ECC and CON trials, respectively (Figure $2 \mathrm{~d}$ ). The [La] was higher during ECC than CON $(p<0.05$; size effect $=0.3$; power $=0.6)$, particularly after the 4 th bout of bicycling exercise. Maximal isometric force was decreased at the end of the experiment by 15.4 and $15.0 \%$ in the CON and ECC trials, respectively, as compared to initial values (both $p<0.05$ ) (Figure 3 ).

Twenty-four hours after the cycling bouts the RER was reduced by approximately 0.04 in both conditions $(p<0.05)$, due to enhanced $\mathrm{VCO}_{2}(p<0.05)$. However, RER values were similar to the control conditions 4 days later. During the control tests performed 1, 2, and 4 days after the CON and ECC protocols, similar values of $\dot{\mathrm{VO}}_{2}, \mathrm{~V}_{\mathrm{E}}, \mathrm{RR}, \mathrm{Vt}, \mathrm{PETO}_{2}, \mathrm{PETCO}_{2}, \mathrm{HR}$, and MVC were obtained. Cycling efficiency was completely restored $24 \mathrm{hrs}$ after the CON and ECC protocols (paired $t$-test, $p=0.7$; power $=0.05$, in both cases CON and ECC) (Figure 4a). Exercise [La] was similarly decreased $24 \mathrm{hrs}$ after the CON and ECC protocols, but was restored to control values $48 \mathrm{hrs}$ after the end of both trials (Figure 4b). Despite this the ECC was followed by marked muscle soreness 1 and 2 days later $(6.6 \pm 0.6$ and $7.1 \pm 0.7$ points, respectively, on a scale from 0 to 10$)$. No effect of eccentric exercise on cycling efficiency or exercise [La] response was observed 1 , 2 , and 4 days after the end ECC protocol. 

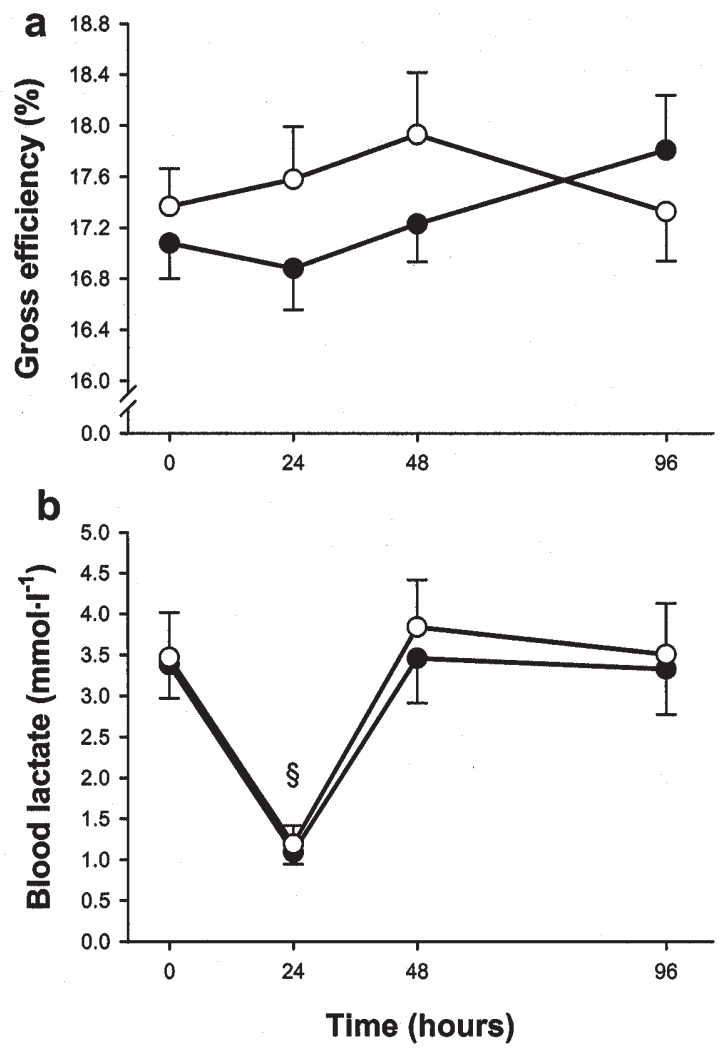

Figure 4. Gross cycling efficiency and blood lactate response to cycling exercise at $65 \% \dot{\mathrm{V}}_{2} \mathrm{max}$, before and after performing prolonged intermittent cycling exercise at $65 \%$ $\dot{\mathrm{V}} \mathrm{O}_{2}$ max with and without eccentric exercise. White circles represent the condition without eccentric exercise; black circles represent the condition in which subjects performed 25 reps of eccentric squatting exercise with a load equivalent to $150 \%$ of body mass after each bout of cycling exercise. $\S p<0.05$ compared to the value observed before eccentric exercise.

\section{EXPERIMENT 2}

During the eccentric exercise protocol, subjects displaced 25,116 $\pm 2,148 \mathrm{~kg}$ (total mass lifted during the experiment). Prior to eccentric exercise the subjects reported no muscle soreness $(0.5 \pm 0.2$ points on a scale from 0 to 10 points), but 1 hour afterward they reported some muscle soreness ( $3.3 \pm 0.6$ points), which peaked $48 \mathrm{hrs}$ later ( $6.7 \pm 0.8$ points). However, 7 days after the eccentric exercise, no muscle soreness was reported ( $0.6 \pm 0.3$ points).

Cycling $\dot{\mathrm{VO}}_{2}$ was not significantly increased 1 hour after eccentric exercise $(+5 \%, p=0.11$; power $=0.2)$. However, 1,2 , and 7 days after the end of eccentric exercise, $\dot{\mathrm{VO}}_{2}$ was similar to control conditions (Figure 5a). $\dot{\mathrm{V}} \mathrm{CO}_{2}$ was not influenced by eccentric exercise. RER was slightly reduced 1 hour after eccentric exer- 

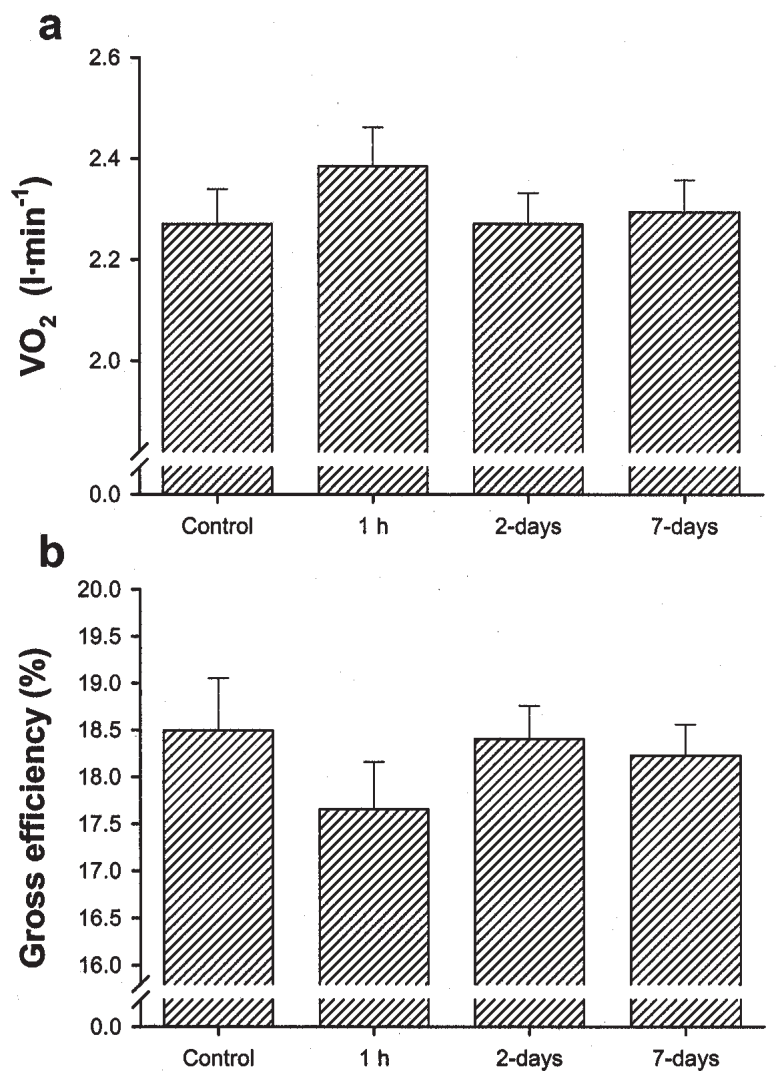

Figure 5. Oxygen uptake and gross cycling efficiency during cycling exercise at $62 \%$ $\dot{\mathrm{V}} \mathrm{O}_{2} \max$, before and after performing eccentric squatting exercise to exhaustion (Experiment E2). $p<0.05$ compared to the value observed before eccentric exercise.

cise (0.014 units, $p=0.07$, while it was increased by 0.024 units 2 and 7 days after eccentric exercise $(p<0.05)$. Cycling efficiency showed a marginal trend to a lower value 1 hour after the termination of eccentric exercise (from $18.5 \pm 0.6$ to $17.7 \pm 0.5 \%, p=0.13$; power $=0.2$ ). However, 2 and 7 days later, cycling efficiency was almost identical to that observed prior to eccentric exercise (Figure 5b). Exercise $\mathrm{PETO}_{2}, \mathrm{PETCO}_{2}$, and $\mathrm{V}_{\mathrm{E}}$ were not affected by eccentric exercise. In contrast, the respiratory rate was slightly increased 1 hour $(+6 \%, p=0.07)$ and 48 hours after eccentric exercise $(+9 \%, p<0.05)$, but it was normalised 5 days later. Conversely, tidal volume tended to be reduced 48 hours following eccentric exercise $(-9 \%, p=0.08)$.

The heart rate response to exercise was increased by $5 \%$ (from $137 \pm 4$ to $144 \pm 3$ beats $\left.\cdot \mathrm{min}^{-1}, p<0.05\right) 1$ hour after the termination of eccentric exercise, but was identical to control conditions 2 and 7 days later. One hour after the end of 


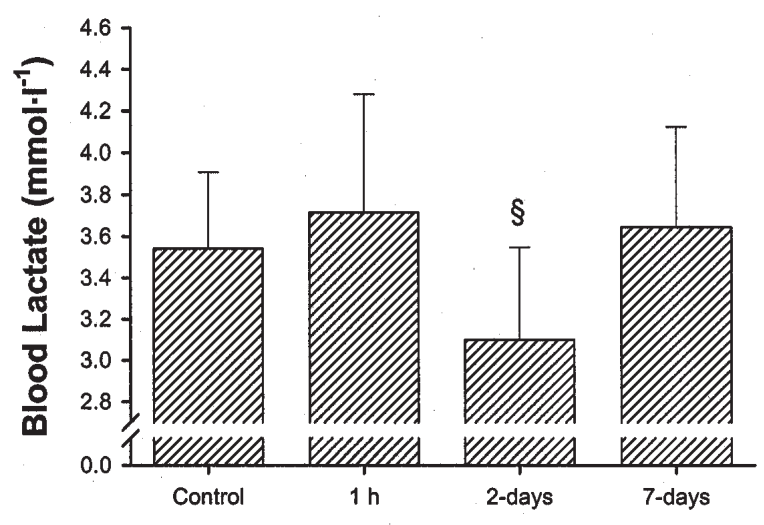

Figure 6. Blood lactate response to cycling exercise at $62 \% \dot{\mathrm{VO}}_{2} \mathrm{max}$, before and after performing eccentric squatting exercise to exhaustion (Experiment E2). $\S p<0.05$ compared to the value observed before eccentric exercise.

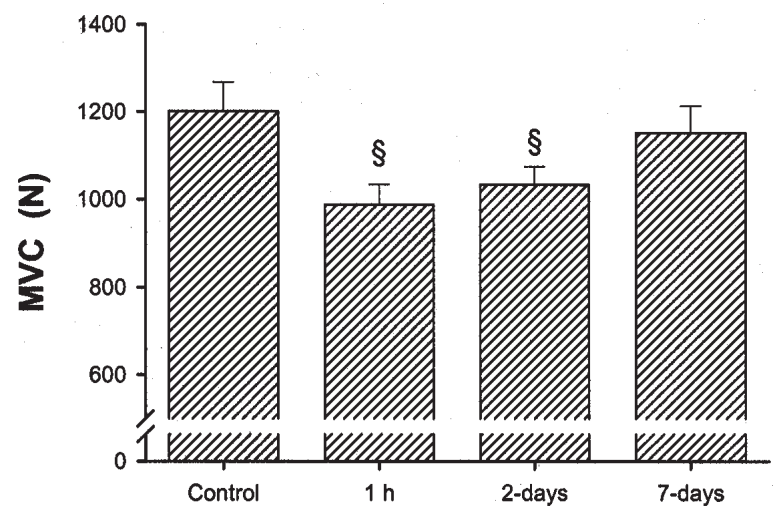

Figure 7. Maximal voluntary contraction (MVC) measured in the squatting position (knees bent at $90^{\circ}$ ), before and after performing eccentric squatting exercise to exhaustion (Experiment E2). $\S p<0.05$ compared to the value observed before eccentric exercise.

eccentric exercise, the blood lactate response to cycling exercise was similar to that observed beforehand. However, 2 days later the blood lactate concentration during cycling was reduced by $12 \%(p<0.01)$. A normal blood lactate response to exercise was observed at 7 days posteccentric exercise (Figure 6). Maximal isometric leg extension force was decreased by $18 \% 1$ hour after the termination of eccentric exercise $(p<0.05)$. Two days later MVC was still $14 \%$ lower than before the eccentric exercise $(p<0.05)$, but it was normalised 7 days after eccentric exercise (Figure 7). 


\section{Discussion}

This study shows that cycling efficiency decreases during prolonged exercise and that, contrary to our hypothesis, eccentric exercise does not accelerate the decline in cycling efficiency usually observed with prolonged cycling exercise. The study also demonstrates that interposing eccentric squatting exercise between bouts of cycling exercise elicits a higher blood lactate concentration without modifying the contribution of fat and carbohydrate oxidation to overall energy yield. In addition, it has also been shown that the loss of isometric force evoked by prolonged cycling was not accentuated by adding a substantial volume of eccentric exercise. Furthermore, this investigation suggests that MVC recovers faster if eccentric exercise is combined with concentric exercise, while more than 2 days are needed to restore MVC when eccentric exercise is performed alone.

\section{EFFECTS OF PROLONGED CYCLING EXERCISE}

The oxygen cost of prolonged exercise at constant intensity depends on the duration and relative intensity of exercise, as well as on the form of muscle contraction (Brueckner et al., 1991; Davies and Thompson, 1986; Guezennec et al., 1996; Hagberg et al., 1978; Kyrolainen et al., 2000; Tonkonogi et al., 1988; Whipp and Wasserman, 1972). The increase of $\dot{\mathrm{VO}}_{2}$ at the end of submaximal exercise observed in our study is similar to that previously reported for continuous cycling exercise of similar duration and intensity (Gonzalez-Alonso et al., 1998; Tonkonogi et al., 1998), but lower than the $16 \%$ increase observed at the end of a marathon run (Kyrolainen et al., 2000).

The physiological mechanism responsible for the ascending drift of $\dot{\mathrm{VO}}_{2}$ with the duration of exercise remains unidentified. It may be speculated that the upward drift of $\dot{\mathrm{VO}} 2$ is caused by increased ATP utilisation due to decreased mechanical efficiency and/or reduced efficiency in ATP production, i.e., decreased efficiency in the energy transfer (P/O ratio). In theory, factors such as hyperthermia, increased plasma catecholamines, changes in mitochondrial respiration (Tonkonogi et al., 1998; Willis and Jackman, 1994), alterations in sarcoplasmic reticulum function (Tupling, 2004; Warren et al., 1996), increased recruitment of type II fibers (Krustrup et al., 2004a, 2004b), and impairment of intermuscular coordination could contribute to increase ATP utilisation (Kyrolainen et al., 2000). However, neither hyperthermia (Gonzalez-Alonso et al., 1998) nor adrenaline infusion or betablockade (Mora-Rodriguez et al., 2001) alter $\mathrm{V}_{2}$ during prolonged submaximal exercise.

During prolonged exercise of moderate intensity it is mostly type I fibers that are recruited, but as fatigue develops, type II fibers are also activated to maintain the same power output (Gollnick et al., 1973). The latter leads to higher exercise $\mathrm{VO}_{2}$ since the mechanical efficiency of type II fibers is lower than that of type I fibers (Crow and Kushmerick, 1982; Krustrup et al., 2004b). Fatigue may also reduce the coordination between synergistic muscles and the agonist-antagonist coordination, as suggested by Kyrolainen et al. (2000).

On the other hand, a substrate shift from carbohydrate to fat might contribute to $\dot{\mathrm{VO}}_{2}$ drift, since more $\mathrm{O}_{2}$ is needed to maintain a given ATP flux when fats rather than carbohydrates are oxidised. However, our study shows that substrate shift only accounts for part of the $\mathrm{VO}_{2}$ increase with exercise duration. More im- 
portant, the substrate mixture oxidised was not altered by the addition of eccentric exercise, neither acutely nor in the days following eccentric exercise. This finding is in agreement with the work of Walsh et al. (2001), who studied the effect of eccentric cycling on muscle oxidative metabolism. In the present study blood lactate concentration was higher when cycling was combined with eccentric squatting exercise than when cycling exercise was performed alone. Twenty-four hours later, however, blood lactate response to cycling was similar in both conditions. Compared to control conditions, the experiment E2 (eccentric exercise performed alone) did not alter the blood lactate response to cycling exercise 1 hour after the end of eccentric exercise.

In contrast, Gleeson et al. (1995) reported elevated blood lactate together with a shift to greater carbohydrate oxidation 2 days after $30 \mathrm{~min}$ of bench stepping (47-cm step, 15 steps $\cdot \mathrm{min}^{-1}$ ). The discrepancy between our results and those of Gleeson et al. are probably related to differences in the eccentric exercise model. However, given the fact that the volume of eccentric work performed by our subjects was greater than that performed by the subjects in Gleeson et al.'s study, a higher alteration of muscle metabolism was expected in our study. Nevertheless, 48 hours after the end of eccentric exercise, muscle oxidative metabolism was similar to control conditions.

The ascending $\mathrm{VO}_{2}$ drift during prolonged exercise is more accentuated when the exercise involves eccentric muscle contractions, such as with downhill running (Dick and Cavanagh, 1987; Westerlind et al., 1992) or eccentric cycling (Klausen and Knuttgen, 1971). It has been suggested that running economy may deteriorate during prolonged exercise due to the muscle damage caused by the eccentric component of the exercise (Kyrolainen et al., 2000). Although eccentric squatting exercise causes muscle damage presumably in the same muscle groups recruited during cycling, the present study shows that eccentric exercise does not accelerate the decline in cycling efficiency elicited by the duration of exercise. Moreover, Experiment E2 indicates that cycling $\mathrm{VO}_{2}$ may be increased at the most by $5 \%, 1$ hour after the end of eccentric exercise (if a type II error is assumed due to insufficient statistical power). Although at first glance this increase in $\mathbf{V O}_{2}$ may seem small, it is not irrelevant since a drift of this magnitude has been associated with reduced exercise performance (Passfield and Doust, 2000). It is worth noting that both experiments (E1 and E2) show no effect of intense muscle soreness on cycling efficiency 48 hours after eccentric exercise.

Can muscle damage and its accompanying functional impairment be attenuated by warm- up?

Nosaka and Clarkson (1997) reported that warming-up with 100 concentric arm flexion actions attenuated the muscle damage induced by subsequent eccentric exercise of the arm flexors. In the present study we had a condition in which the subjects performed 20 min of cycling exercise at $65 \% \mathrm{VO}_{2}$ max prior to eccentric exercise (CON-ECC protocol), and another condition in which they did not perform concentric exercise prior to eccentric exercise (pure eccentric exercise protocol). By comparing both conditions it can be concluded that concentric exercise does not attenuate the loss of muscle strength caused by eccentric exercise, as previously reported (Evans et al., 2002; Nosaka and Clarkson, 1997). However, 
when eccentric exercise was preceded by and combined with cycling exercise, the recovery of muscle strength was complete even at 24 hours, whereas it was still reduced 48 hours after the end of eccentric exercise performed without concentric exercise.

Our results agree with those of Nosaka and Clarkson (1977), who also observed a faster recovery of MVC when the eccentric exercise bout was preceded by concentric exercise. Perhaps the concentric muscle contractions performed during the 10 min of bicycling exercise have a protective effect, attenuating the muscle damage caused by the bouts of eccentric squatting exercise. With less muscle damage, muscle force may be recovered faster. This may be the reason why muscle strength was normalised the next morning in our experiments, while it took a little more time in the Nosaka and Clarkson study. In contrast to Nosaka and Clarkson (1977), but in agreement with Evans et al. (2002), concentric exercise had no significant effect on the level of muscle pain elicited by eccentric exercise and its recovery. The fact that muscle pain was similar, but force recovered faster when the subjects combined concentric and eccentric exercise, suggests that muscle pain per se has no role in the reduction of muscle strength after eccentric exercise.

It has been reported that the loss of muscle strength after eccentric exercise is caused by both peripheral (Ingalls et al., 1998; McBride et al., 2000; Michaut et al., 2002; Warren et al., 1993; Yeung et al., 2002) and central (Gibala et al., 1995; Michaut et al., 2002; Millet et al., 2003) mechanisms. Among the peripheral mechanisms, animal experiments have provided compelling evidence for a failure in neuromuscular transmission and sarcolemmal excitability, caused by excitationcontraction uncoupling (Ingalls et al., 1998; Warren et al., 1993; Yeung et al., 2002) and persistent activation of mechanosensitive or stretch-activated ion channels (McBride et al., 2000).

Evidence for a central failure in maximal muscle activation following eccentric exercise has been obtained using the twitch-interpolation technique. This technique compares the force generated during a maximal concentric voluntary contraction with that elicited when an electrical discharge is superimposed on a maximal voluntary isometric contraction. If electrical stimulation allows for a greater development of force, then it is assumed that there is a deficit of neural activation. Using the twitch interpolation technique, it has been reported that following eccentric exercise or prolonged running there is a deficit of neural activation (Gibala et al., 1995; Michaut et al., 2002; Millet et al., 2003). Also, it has been postulated that pain or reflexes triggered by inflammation mediators or catabolites released during and/or following eccentric exercise may attenuate the corticospinal drive at either the supraspinal or spinal level, reducing the output of the alphamotoneurons (Millet et al., 2003).

More experiments will be needed to determine by which mechanisms a recovery of strength is facilitated when eccentric exercise is combined with concentric exercise. It may be of particular interest to determine if the degree of muscle damage is attenuated when the eccentric exercise is combined with concentric exercise. It could also be of interest to determine if this combination of exercise prevents the persistent activation of mechanosensitive or stretch-activated ion channels described by McBride et al. (2000). Finally, whether the combination of eccentric and concentric exercise prevents the impairment in the process of neural activation observed when eccentric exercise is performed alone needs to be established. 
In summary, this study shows that eccentric exercise does not reduce cycling efficiency either acutely or in the days that follow, even when the subjects experience intense delayed muscle soreness and loss of muscle strength. By performing concentric exercise before and between the series of eccentric exercise, subjects recover their strength faster than when performing eccentric exercise alone.

\section{Acknowledgments}

Study supported by a grant from the Fundación Universitaria de Las Palmas de Gran Canaria.

\section{References}

Appell, H.J., Soares, J.M., and Duarte, J.A. (1992). Exercise, muscle damage and fatigue. Sports Med. 13: 108-115.

Braun, W.A., and Dutto, D.J. (2003). The effects of a single bout of downhill running and ensuing delayed onset of muscle soreness on running economy performed $48 \mathrm{~h}$ later. Eur. J. Appl. Physiol. 90: 29-34.

Brueckner, J.C., Atchou, G., Capelli, C., Duvallet, A., Barrault, D., Jousselin, E., Rieu, M., and di Prampero, P.E. (1991). The energy cost of running increases with the distance covered. Eur. J. Appl. Physiol. Occup. Physiol. 62: 385-389.

Calbet, J.A., Chavarren, J., and Dorado, C. (2001). Running economy and delayed onset muscle soreness. J. Sports Med. Phys. Fitness 41: 18-26.

Carreño, J.A., Cortadellas, J., Arteaga, R., and Calbet, J.A.L. (2001). Strength loss and recovery after squat eccentric exercise to exhaustion. In: J. Mester, G. King, H. Strüder, E. Tsolakidis, and A. Osterburg (Eds.), 6th Annual Congress of the European College of Sport Science. Book of Abstracts, p. 1057. Cologne, Germany: Sport und Bunch Strauss GmbH.

Cheung, K., Hume, P., and Maxwell, L. (2003). Delayed onset muscle soreness: Treatment strategies and performance factors. Sports Med. 33: 145-164.

Crow, M.T., and Kushmerick, M.J. (1982). Chemical energetics of slow- and fast-twitch muscles of the mouse. J. Gen. Physiol. 79: 147-166.

Davies, C.T., and Thompson, M.W. (1986). Physiological responses to prolonged exercise in ultramarathon athletes. J. Appl. Physiol. 61: 611-617.

Dick, R.W., and Cavanagh, P.R. (1987). An explanation of the upward drift in oxygen uptake during prolonged sub-maximal downhill running. Med. Sci. Sports Exerc. 19: 310-317.

Dorado, C., Sanchis-Moysi, J., and Calbet, J.A. (2004). Effects of recovery mode on performance, $\mathrm{O}_{2}$ uptake, and $\mathrm{O}_{2}$ deficit during high-intensity intermittent exercise. Can. J. Appl. Physiol. 29: 227-244.

Evans, R.K., Knight, K.L., Draper, D.O., and Parcell, A.C. (2002). Effects of warm-up before eccentric exercise on indirect markers of muscle damage. Med. Sci. Sports Exerc. 34: 1892-1899.

Gibala, M.J., MacDougall, J.D., Tarnopolsky, M.A., Stauber, W.T., and Elorriaga, A. (1995). Changes in human skeletal muscle ultrastructure and force production after acute resistance exercise. J. Appl. Physiol. 78: 702-708.

Gleeson, M., Blannin, A.K., Zhu, B., Brooks, S., and Cave, R. (1995). Cardiorespiratory, hormonal and haematological responses to submaximal cycling performed 2 days after eccentric or concentric exercise bouts. J. Sports Sci. 13: 471-479. 
Gollnick, P.D., Armstrong, R.B., Sembrowich, W.L., Shepherd, R.E., and Saltin, B. (1973). Glycogen depletion pattern in human skeletal muscle fibers after heavy exercise. J. Appl. Physiol. 34: 615-618.

Gonzalez-Alonso, J., Calbet, J.A., and Nielsen, B. (1998). Muscle blood flow is reduced with dehydration during prolonged exercise in humans. J. Physiol. 513(Pt 3): 895905.

Guezennec, C.Y., Vallier, J.M., Bigard, A.X., and Durey, A. (1996). Increase in energy cost of running at the end of a triathlon. Eur. J. Appl. Physiol. Occup. Physiol. 73: 440445.

Hagberg, J.M., Mullin, J.P., and Nagle, F.J. (1978). Oxygen consumption during constantload exercise. J. Appl. Physiol. 45: 381-384.

Horita, T., Komi, V., Hamalainen, I., and Avela, J. (2003). Exhausting stretch-shortening cycle (SSC) exercise causes greater impairment in SSC performance than in pure concentric performance. Eur. J. Appl. Physiol. 88: 527-534.

Ingalls, C.P., Warren, G.L., Williams, J.H., Ward, C.W., and Armstrong, R.B. (1998). E-C coupling failure in mouse EDL muscle after in vivo eccentric contractions. J. Appl. Physiol. 85: 58-67.

Klausen, K., and Knuttgen, H.G. (1971). Effect of training on oxygen consumption in negative muscular work. Acta Physiol. Scand. 83: 319-323.

Krustrup, P., Soderlund, K., Mohr, M., and Bangsbo, J. (2004a). The slow component of oxygen uptake during intense, sub-maximal exercise in man is associated with additional fibre recruitment. Pflugers Arch. 447: 855-866.

Krustrup, P., Soderlund, K., Mohr, M., and Bangsbo, J. (2004b). Slow-twitch fiber glycogen depletion elevates moderate-exercise fast-twitch fiber activity and $\mathrm{O}_{2}$ uptake. Med. Sci. Sports Exerc. 36: 973-982.

Kyrolainen, H., Pullinen, T., Candau, R., Avela, J., Huttunen, P., and Komi, P.V. (2000). Effects of marathon running on running economy and kinematics. Eur. J. Appl. Physiol. 82: 297-304.

Lieber, R.L., and Friden, J. (1999). Mechanisms of muscle injury after eccentric contraction. J. Sci. Med. Sport 2: 253-265.

Lieber, R.L., Thornell, L.E., and Friden, J. (1996). Muscle cytoskeletal disruption occurs within the first $15 \mathrm{~min}$ of cyclic eccentric contraction. J. Appl. Physiol. 80: 278-284.

McBride, T.A., Stockert, B.W., Gorin, F.A., and Carlsen, R.C. (2000). Stretch-activated ion channels contribute to membrane depolarization after eccentric contractions. J. Appl. Physiol. 88: 91-101.

Michaut, A., Pousson, M., Babault, N., and Van Hoecke, J. (2002). Is eccentric exerciseinduced torque decrease contraction type dependent? Med. Sci. Sports Exerc. 34: 1003-1008.

Millet, G.Y., Martin, V., Lattier, G., and Ballay, Y. (2003). Mechanisms contributing to knee extensor strength loss after prolonged running exercise. J. Appl. Physiol. 94: 193198.

Mora-Rodriguez, R., Hodgkinson, B.J., Byerley, L.O., and Coyle, E.F. (2001). Effects of beta-adrenergic receptor stimulation and blockade on substrate metabolism during submaximal exercise. Am. J. Physiol. Endocrinol. Metab. 280: E752-E760.

Nosaka, K., and Clarkson, P.M. (1997). Influence of previous concentric exercise on eccentric exercise-induced muscle damage. J. Sports Sci. 15: 477-483. 
Nosaka, K., Newton, M., and Sacco, P. (2002). Muscle damage and soreness after endurance exercise of the elbow flexors. Med. Sci. Sports Exerc. 34: 920-927.

Passfield, L., and Doust, J.H. (2000). Changes in cycling efficiency and performance after endurance exercise. Med. Sci. Sports Exerc. 32: 1935-1941.

Perneger, T.V. (1998). What's wrong with Bonferroni adjustments. Br. Med. J. 316: 12361238.

Peronnet, F., and Massicotte, D. (1991). Table of nonprotein respiratory quotient: An update. Can. J. Sport Sci. 16: 23-29.

Peterson, J.M., Trappe, T.A., Mylona, E., White, F., Lambert, C.P., Evans, W.J., and Pizza, F.X. (2003). Ibuprofen and acetaminophen: Effect on muscle inflammation after eccentric exercise. Med. Sci. Sports Exerc. 35: 892-896.

Rodenburg, J.B., Bar, P.R., and De Boer, R.W. (1993). Relations between muscle soreness and biochemical and functional outcomes of eccentric exercise. J. Appl. Physiol. 74: 2976-2983.

Tidball, J.G. (2002). Interactions between muscle and the immune system during modified musculoskeletal loading. Clin. Orthop. 403S: S100-S109.

Tonkonogi, M., Harris, B., and Sahlin, K. (1998). Mitochondrial oxidative function in human saponin-skinned muscle fibres: Effects of prolonged exercise. J. Physiol. 510(Pt 1): $279-286$.

Tupling, A.R. (2004). The sarcoplasmic reticulum in muscle fatigue and disease: Role of the sarco(endo)plasmic reticulum $\mathrm{Ca}^{2+}$-ATPase. Can. J. Appl. Physiol. 29: 308-329.

Walsh, B., Tonkonogi, M., Malm, C., Ekblom, B., and Sahlin, K. (2001). Effect of eccentric exercise on muscle oxidative metabolism in humans. Med. Sci. Sports Exerc. 33: 436-441.

Warren, G.L., 3rd, Williams, J.H., Ward, C.W., Matoba, H., Ingalls, C.P., Hermann, K.M., and Armstrong, R.B. (1996). Decreased contraction economy in mouse EDL muscle injured by eccentric contractions. J. Appl. Physiol. 81: 2555-2564.

Warren, G.L., Hayes, D.A., Lowe, D.A., and Armstrong, R.B. (1993). Mechanical factors in the initiation of eccentric contraction-induced injury in rat soleus muscle. J. Physiol. 464: 457-475.

Warren, G.L., Lowe, D.A., and Armstrong, R.B. (1999). Measurement tools used in the study of eccentric contraction-induced injury. Sports Med. 27: 43-59.

Westerlind, K.C., Byrnes, W.C., and Mazzeo, R.S. (1992). A comparison of the oxygen drift in downhill vs. level running. J. Appl. Physiol. 72: 796-800.

Whipp, B.J., and Wasserman, K. (1972). Oxygen uptake kinetics for various intensities of constant-load work. J. Appl. Physiol. 33: 351-356.

Willis, W.T., and Jackman, M.R. (1994). Mitochondrial function during heavy exercise. Med. Sci. Sports Exerc. 26: 1347-1353.

Yeung, E.W., Balnave, C.D., Ballard, H.J., Bourreau, J.P., and Allen, D.G. (2002). Development of T-tubular vacuoles in eccentrically damaged mouse muscle fibres. J. Physiol. 540: 581-592.

Yu, J.G., Furst, D.O., and Thornell, L.E. (2003). The mode of myofibril remodelling in human skeletal muscle affected by DOMS induced by eccentric contractions. Histochem. Cell Biol. 119: 383-393.

Received January 5, 2004; accepted in final form September 20, 2004. 